\section{LE CID, DE CORNEILLE, - TEATRO CLÁsSICO FRANCÊS, E A GÊNESE DO ESTADO MODERNO}

Le Cid, by Corneille, the French Classical Drama and the genesis of the Modern State

\section{Carlos Eduardo \\ Rebello de \\ MENDONÇA}

(D) carloseduardorebellodemendonca@gmail.com

Universidade do Estado

do Rio de Janeiro

Rio de Janeiro, RJ, Brasil

\section{RESUMO}

O artigo homenageia o trabalho de Benzaquen de Araujo \& Viveiros de Castro (1977) sobre Romeu e Julieta, peça shakespeareana que trataria da gênese do Estado Moderno superpondo-se e sobrepondo-se aos interesses privados, fundidos numa "sociedade civil" legalmente indiferenciada. Argumentamos que tal gênese da Sociedade Civil em si só não estabelece um modo de resolução dos conflitos entre interesses privados, o que será a tarefa histórica do Absolutismo. A peça de Corneille, Le Cid, que examinamos, trataria desse papel ativo do Estado pela resolução de uma história de amor e de vendetta. Conclui-se que Corneille e Shakespeare compartilhavam uma certa noção do indivíduo "domesticado", "administrado".

Palavras-chave: Teatro Clássico Francês, Absolutismo, Estado Moderno, Pierre Corneille, Le Cid.

\begin{abstract}
His work is written in honor of the already classical article by Benzaquen de Araujo \& Viveiros de Castro (1977) on Romeo and Juliet, in which the authors argue for the Shakespeare play as explaining the making of the Modern State as above private interests, from then on melded into a legally undifferentiated civil society. We argue that such a making of Civil Society does not in itself explain a mode of resolution for the struggle between various interests, a task historically assumed by Absolute Monarchy. The play by Corneille, Le Cid, which we examine as an ideal case, deals with this resolution mode by means of a story of both love and feud. We conclude by explaining how both Shakespeare and Corneille partook of the same notion of the "managed" individual.
\end{abstract}

Keywords: French Classical Drama, Absolutism, Modern State, Pierre Corneille, Le Cid. 


\section{As tarefas do Estado Moderno}

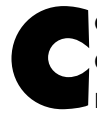

omo escrevem Benzaquen e Viveiros de Castro, quando o pano cai sobre a cena de Romeu e Julieta, a Verona mitológica, que começara a peça dividida pela rixa entre duas famílias aristocráticas, encontra-se agora "normalizada" como uma sociedade homogênea de indivíduos formalmente iguais, sujeitos à mesma lei do Príncipe (BENZAQUEN DE ARAUJO; VIVEIROS DE CASTRO, 1977, p. 148-149). Óbvio que, no entanto, a simples afirmação do "Império da Lei" não cancela as pulsões e interesses privados - e seu potencial de geração de conflitos. A persistência do "malestar" freudiano diante das exigências da Civilização exige que o Estado passe da mera afirmação da autoridade para seu exercício de acordo com um padrão definido. E é isso que iremos procurar não em Shakespeare mas no Teatro Clássico Francês, esta flor de estufa literária do Absolutismo seiscentista.

Conforme Auerbach (1987, p. 142), o Classicismo francês caracteriza-se pelo isolamento atmosférico do acontecimento: a ação dramática está confinada num círculo restrito de lugares e acontecimentos (a Corte e as intrigas pelo poder) onde as paixões dos protagonistas se desenrolam em isolamento absoluto. Tudo conforme a tradição herdada da Antiguidade Clássica, de que apenas os acontecimentos sublimes merecem uma forma séria. Tal não implica, no entanto, um descolamento da realidade concreta, e sim em concentração da ação, visando - pela aplicação a mais rigorosa da regra das Três Unidades (tempo, lugar, ação) - sublinhar da forma mais contundente o significado moral desejado. Por debaixo da sua forma sublime, o Classicismo francês é não apenas moralizante como extremamente politizado.

Le Cid (1637), dentro deste corpus literário, é um texto de exceção: pelo tema "contemporâneo", remanejando uma narrativa semi-histórica medieval espanhola; e pelo sucesso de escândalo, que lhe valeu as críticas da Academia Francesa (e do Cardeal Richelieu) e seu remanejamento ulterior. À diferença de Romeu e Julieta e da obra Shakespeareana em geral, cujo impacto público foi principalmente póstumo, a peça de Corneille foi concebida desde o início como algo atual, agindo diretamente sobre a agenda pública da época; trata-se de teatro "engajado". A ousadia básica de Corneille é a de tratar do tema do amor impossível num quadro histórico usando como protagonista uma figura de historicidade inconteste, e, a partir destes dados, escolher a forma da tragicomédia, do conflito que termina em reconciliação, apesar do caráter escandaloso do tema base: um herói que termina por casar-se com a filha de um rival que ele assassinou. Mas é aí que se encontra a grande originalidade do texto: a contrapelo de Romeu e D. Juan, grandes amantes que tem por traço comum o caráter disruptivo das suas paixões, a quebra dos consensos estabelecidos que produzem - o Cid corneilliano é, ao mesmo tempo, grande amoroso e grande defensor da Ordem; é um amante cuja característica distintiva está no seu esforço de subordinar o seu amor à legalidade, ao Império da Lei e à Razão de Estado - wo Es war, soll lch werden. Não para menos, ele tem como uma das suas características mais singulares o elemento não-correspondido da sua paixão, o fato de amar uma mulher que passa boa parte da peça meditando em como matá-lo. 
Nelson Rodrigues uma vez escreveu que nunca houve um herói do sexo, um santo lascivo - pois o desejo, em si, nunca produziu nada além do animalesco; de certa forma, o herói de Corneille é o "cisne negro" popperiano que falsifica tal afirmação: pois nele o desejo de possuir Ximena é tão acentuado quanto o seu desejo de fazêlo de acordo com a Lei.

O núcleo histórico da peça: a figura do El Cid (do árabe sidi, "senhor") um senhor feudal do século XI, vassalo de lealdade duvidosa do rei de Castela, que conseguiu com seu exército particular formar um principado efêmero em Valência, intrigando com todas as partes em presença o tempo todo, fazendo e desfazendo alianças com os reis cristãos e muçulmanos (sendo durante algum tempo agente do Emir de Saragoça) à sua vontade e conveniência - uma figura sem nada particularmente "cavalheiresco", que expressava a indistinção entre o público e o privado própria à Alta Idade Média da Europa Ocidental, assim como a privatização "selvagem" do poder político daí decorrente.

Na Baixa Idade Média, a narrativa começa a sofrer os primeiros acréscimos legendários: os cronistas resolveram atribuir ao herói o ato de ter matado ao sogro num duelo e depois se casado com a filha do morto. Mas este tema do casamento com a filha da vítima não aparecia como uma demonstração de amor cavalheiresco, e sim como penitência e compensação: uma demonstração de justiça comutativa, em que o assassino "indenizava" a vítima restituindo-Ihe as suas prerrogativas... Tratavase de uma noção cara à lógica da vendetta, a do preço do sangue, que assimilava o casamento a uma compensação monetária ou em serviços - tal como a extinção da punibilidade de um estupro pelo casamento da estuprada com o estuprador. Tinha-se aí a ideia de um limite ao exercício da vingança privada: posso matar meu ofensor, mas isso não me dá o direito de exterminar-Ihe a família; sai-se da lógica do "tratar muito bem aos amigos e abominavelmente mal aos inimigos". Como no mito freudiano do Pai da Horda, a penitência legitima o assassinato, mas ao mesmo tempo o limita, o submete à Lei impessoal.

A passagem do Cid da História à lenda e à literatura, portanto, faz-se através de um processo de refinamentos sucessivos, que replica a maneira como o Absolutismo real, a partir do século XV, vai "relendo" politicamente as instituições sociais do Feudalismo: a sociedade é axiomaticamente desigual e hierárquica, as distinções são necessárias e desejáveis (como dirá o Werther de Goethe ainda em pleno século XVIII) - mas há limites. É a culminância de um processo histórico pelo qual o Direito (público) Romano "filtra" as instituições aristocráticas do Direito (privado) germânico: sai-se da lógica do "cada um pega o quanto pode" para a do "cada um toma aquilo a que tem direito".

O passo seguinte deste processo de filtragem seria dado pelo teatrólogo do Século de Ouro espanhol, Guillen de Castro, que, na sua peça Las mocedades del Cid (1605-1615) transformou o dilema moral do Cid num dilema bilateral, em que estavam igualmente envolvidos tanto o herói quanto sua parceira Ximena: o dramaturgo espanhol imagina um noivado entre o Cid e Ximena, anterior ao duelo entre o genro e o sogro putativo, e assim coloca na narrativa o elemento da culpa feminina pela satisfação do desejo - que era precisamente o que torna a narrativa 
básica da história, para muitos, repulsiva: a filha desnaturada que aceita livremente casar-se com o assassino do seu pai. Mas ao fazer Ximena casar-se com o Cid por ordem do Rei, Castro introduz o elemento do dever na história, e, de uma forma moralmente ambígua: trata-se de um caso freudiano em que a pulsão do desejo é desviada quanto ao fim, com a consequência de que aqui o Superego age de forma tão poderosa - e imoral - quanto o ld.

Rubem Braga, que assistiu Le Cid nos anos 1960 numa montagem da Comédie Française nas ruínas romanas de Volubilis no Marrocos, escreveu uma crônica deliciosa sobre sua decepção com uma peça que, nas suas recordações de adolescência, transmitia "sentimentos fidalgos de renúncia, de sacrifício", e oferecia ao adido cultural adulto uma farsa com uma Ximena "boa bisca" que proclamava o desejo de vingar o pai para depois aparecer "quicando" de vontade de juntar-se a Rodrigo/El Cid... Rubem Braga tinha razão, no sentido de que Le Cid, à diferença de Romeu e Julieta (ou, num plano bem diverso, Phèdre de Racine) não pode ser entendida nem assistida como uma história de amor romântico sem tornar-se bizarra, quase farsesca. Já em 1638 os membros da Academia Francesa reclamavam da "inverossimilhança" da peça (não é porque uma filha poderia casar-se com o matador do seu pai que tal ação seja aceitáve/ de representação). Mas no seu contexto histórico específico - o do Absolutismo francês emergente - é que se coloca em pé o ponto propriamente político que justifica a ficção, e que será precisamente o ponto que Corneille - poeta de Corte, acadêmico e enfim nobilitado por um casamento arranjado pelo Cardeal Richelieu - explorará a fundo.

Socialmente falando, o Estado Absolutista europeu é um Feudalismo, com a sua nobreza sendo movida, nos seus interesses políticos espontâneos, pela mesma lógica de vendetta que movia os nobres francos das histórias de Gregório de Tours, sobre as quais Auerbach comenta em Mimesis (AUERBACH, 1987, capítulo 4 - "Sicário e Cramnesindo"): a mesma paixão pelos golpes baixos, a mesma predisposição para a violência incontida. Como escreve uma historiadora marxista, aquilo que caracteriza o Feudalismo da Europa Ocidental como um regime social é exatamente a parcelização da soberania: a comensurabilidade entre direitos privados de propriedade e poder político, a subsunção da esfera pública ao interesse privado (WOOD, 2012, p. 5-6). O Absolutismo da Idade Moderna não alterou as relações sociais básicas que existiam no Ocidente Europeu desde a Alta Idade Média; o que ele fez foi discipliná-las, submetê-las aos interesses políticos do Estado - estes associados primariamente às necessidades militares. Como escreve a historiadora marxista canadense, o discurso filosófico da Modernidade Política é habermasiano, no sentido de que é uma práxis, mas tal práxis não é ontologicamente burguesa: de fato, ela refere-se a um desejo das monarquias absolutistas de uniformizar, regimentar e controlar as condições de exercício do poder político em função da Razão de Estado. Tratava-se, na verdade, de uma Modernidade que se queria como uma restauração da Antiguidade, pela via da aplicação sistemática do Direito Romano, entendido como a expressão da Lei uniforme e racional sobre os costumes prerrogativas e franquias locais. 
Ora, tudo no enredo da peça de Corneille gira em torno da desejada subsunção do espírito aristocrático à legalidade, a uma versão absolutista do "Império da Lei”. O Cid histórico era uma expressão acabada da Alta Idade Média real, em que as funções do Estado estavam fragmentadas, vertical como horizontalmente: não há hierarquias bem definidas e as posições de poder de cada um são fluidas (WOOD, 2008, p. 166). "Todos intrigam com todos [... ] não há oposições sistemáticas" (VEYNE, 2005 , p. 735). E esse jogo meio maquiavélico, meio hobbesiano, estende-se para dentro da Renascença, da Idade Moderna, e das Guerras de Religião, que muito farão para estimular o jogo interaristocrático das lealdades divididas, das reversões de alianças e das combinações secretas e das traições. Como lembra Meikisins Wood (2012, p. 170), a emergência do Estado Moderno (exceto, parcialmente, no caso inglês) tem menos a ver com a emergência do Indivíduo Burguês como sujeito de direitos individuais do que com a noção, principalmente francesa, do Estado como "uma única vontade harmonizadora, [através da qual] uma rede de entidades corporativas [seria] integrada numa totalidade orgânica e hierárquica por um único poder soberano". É certo que em Le Cid estamos diante do mundo da Sociedade de Corte de Norbert Elias, como coroamento de um processo civilizatório, de "domesticação" dos costumes; mais do que isso, estamos dentro do mundo político do Absolutismo francês, tal como ele desejaria idealmente ser, com o Rei como única fonte de toda e qualquer legalidade.

\section{Uma peça e seus problemas}

Quando Corneille publica, em 1648, uma edição revisada da sua peça, o seu grande problema era o de responder às censuras dos seus contemporâneos, dentro e fora da Academia, quanto ao enredo chocante da sua produção: se em Romeu e Julieta os amantes terminam a peça ambos igualmente mortos - morte que é o penhor da "sombria paz" que desce sobre o espaço público da Verona fictícia (BENZAQUEN DE ARAUJO; VIVEIROS DE CASTRO, 1977, p. 146), em Le Cid o grande problema é como escrevia em 1637 o relator das críticas da Academia, Chapelain - o seu assunto "defeituoso", no sentido de incomum, i.e., logicamente inconsistente : "pois o poeta não respeita ali o decoro [bienséance] próprio a uma jovem que ele descreve como virtuosa, quando esta resolve-se a esposar a quem matou seu pai [...] consentindo neste casamento em virtude da simples violência cometida pelo seu amor"(In: CORNEILLE, 1959, p. 16). O que equivale a dizer que tal desfecho seria logicamente imoral, na medida em que ambos os amantes terminam a peça vivos e dispostos a gozarem da recompensa de um crime que clamava aos céus por vingança.

A resposta de Corneille, no seu prefácio de 1648, em defesa da sua escolha narrativa, é extremamente esclarecedora: ele cita uma personagem de outra peça de Guillen de Castro, que enuncia a noção de que "la que el desear/com el resistir apunta/vence dos veces, si junta/com el resistir el callar" - ou seja, a resistência feminina ao desejo é tanto mais meritória se é realizada em silêncio. E completa Corneille: 
C'est, sije ne me trompe, comme agit Chiméne dans mon ouvrage, en presénce du Roi et de l'Infante [...] Quand elle est seule, ou avec sa confidente, ou avec son amant, c'est une autre chose.

É desta forma, se não me engano, que age Ximena na minha obra, quando na presença do Rei e da Infanta [...] Quando só, com sua confidente ou seu amante, trata-se de outra coisa. (CORNEILLE, 1959, p. 23).

Ou seja, o grande mérito de Ximena seria não o de não desejar o assassino do seu pai, mas de, em desejando-o, calar no espaço público e expressá-lo apenas em privado... Não para menos, a maneira como Corneille trata do desejo sexual feminino replica os tropos do discurso absolutista contemporâneo a respeito do problema religioso e da liberdade de consciência: cada um é livre para crer no que quiser e praticar sua confissão religiosa no espaço privado, desde que, no espaço público, mostre o respeito exigido à religião de estado. Cuius regio, eius religio (KOSELLECK, 1999, Cap. I). Mais interessante ainda é que Corneille faça implicitamente de Ximena a protagonista oculta da peça, na medida em que é ela que, mais do que o Cid, conforma seu comportamento e suas escolhas ao Imperativo Moral encarnado na Lei positiva - quando convertida na vontade Régia.

Chapelain, na sua crítica da peça, alude a este problema muito negativamente: para ele, na peça, “o desfecho da intriga só se torna possível por um ato de inesperada injustiça do Rei Fernando, que ordena um casamento que em sã consciência ele não deveria sequer propor" (CORNEILLE, 1959, p. 116). Só que- além de mergulhar Ximena na negação histérica - recusar a possibilidade do casamento impossibilitaria a reconciliação; sendo a única alternativa possível ao perdão a condenação do Cid, tal alternativa, além de deixar a rixa em "aberto" e ofender a razão de Estado, como diz um dos romanceiros espanhóis citados por Corneille (Al Cid no lo he de ofender) que es hombre que mucho vale/y me defiende mis reynos) (In: CORNEILLE, 1959, p. 26), deixaria de reconhecer a realidade objetiva mesmo do desejo de Ximena - e com ele a "verdade efetiva das coisas" de Maquiavel. Tal seria, do ponto de vista do Rei, governar sem levar em conta as paixões humanas, como descrito pelo contemporâneo de Corneille, Spinoza:

Procurei escrupulosamente não rir, nem chorar, nem detestar as ações humanas, mas entendê-las. Assim, não encarei os afetos humanos [...] como vícios da natureza humana, mas como propriedades que Ihe pertencem [...] os quais, embora sejam incômodos, são contudo necessários e tem causas certas. (ESPINOSA, 2009, p. 8)

O desejo sexual de Ximena é incômodo - mas é precisamente o que torna o enredo da peça verossímil, na medida em que é o que desloca o enredo do tema da vingança para o da reconciliação; é a pedra que desarranja toda a engrenagem.

Talvez a causa da diferença entre a popularidade perene e anacrônica de Romeu e Julieta, em oposição a Le Cid em particular - e ao Teatro Clássico Francês em geral 
- deva-se as diferenças nos seus contextos histórico-políticos respectivos: de um lado Shakespeare, dramaturgo sem biografia, homem comum e membro da "multidão", que vê a relação entre o Estado e a Sociedade Civil de um ponto de vista hobbesiano: o que interessa ao povo comum nas dissensões entre os grandes é apenas que elas cessem, que exista um único centro de autoridade indiscutível: pois "a multidão expressa sua existência política, não pela resistência ao governo tirânico, mas pela abdicação do direito de resistência" (WOOD, 1997, p. 98). A Verona reconciliada do desfecho da peça shakespeariana é uma Verona onde o espaço público foi esvaziado, no dizer do Príncipe, das alegrias das rixas aristocráticas: See, what a scourge is laid upon your hate/ That heaven finds means to kill your joys with love.

Tal não é, evidentemente, o ponto de vista de Corneille, que, longe de ser um dramaturgo popular que se limita a falar nos textos, é também cortesão de Luis XIII com uma carreira a zelar: todo o escândalo em torno do enredo do Le Cid foi originalmente uma tentativa (fracassada, aliás) de intrigar o autor junto ao Cardeal - da qual Corneille saiu-se com um brasão de armas concedido ao seu pai (In: CORNEILLE, 1959, p. 15). O ponto de vista político de Corneille é tipicamente francês, na medida em que nele a autoridade do Estado não está referida à preservação da vida e do indivíduo, mas à manutenção de uma hierarquia racional - algo mais ligado à noção de mérito ("carreiras abertas a todos os talentos") (WOOD, 2012, p. 172) do que a de igualdade. É como se a oposição entre Shakespeare e Corneille fosse a representação antecipada da oposição entre dois elementos mutuamente contraditórios do futuro Liberalismo Burguês: "igualdade" passiva (direito à vida) vs. desigualdade ativa ("honra ao mérito").

\section{A peça em si: análise}

Quando o texto do Le Cid se abre, estamos no palácio sevilhano do Rei Fernando de Castela, onde o pai de Ximena, D. Gomes, está muito bem disposto quanto ao possível enlace da sua filha com D. Rodrigo, filho do velho nobre D. Diego. Ocorre que D. Gomes contava obter o cargo de preceptor do Príncipe herdeiro, que é concedido em conselho, no entanto, ao pai do seu genro presuntivo, não obstante sua idade avançada e reduzida capacidade física. Sentindo-se preterido pelo rei, D. Gomes lembra D. Diego da comum falibilidade humana:

- Pour grands que soient les rois, ils sont ce que nous sommes: Ils peuvent se tromper comme les autres hommes

[- Por grande que um rei seja, é como nós humanos;

Como outro homem também, passível é de engano;)

(I, iii, 157-158) ${ }^{1}$

Ao que D. Diego responde pelo argumento hobbesiano de que é dever do súdito abdicar da sua liberdade de julgamento em prol da paz civil:

Mais on doit ce respect au pouvoir absolu

De n'examiner rien quand un roi l'a voulu

[Mas faz-se, na obediência ao poder real, mister

Em nada examinar-se aquilo que um rei quer.]

(I, iii, 163-164) 
A que D. Gomes responde acusando D. Diego de ter conseguido o posto através da intriga [brigue] e o esbofeteia, escarnecendo da sua idade e incapacidade física, e convidando-o a "instruir" o Príncipe na sua fraqueza:

Fais lire au Prince, en dépit de l'envie / Pour son instruction, l'histoire de ta vie;

[Ao príncipe dá a ler, grava-Ihe na memória/Sem embargo da inveja, a tua vida e história;]

(I, iii, 233-234)

A disputa entre D. Gomes e D. Diego é falsa, num contexto da Alta Idade Média; mas Corneille, que vê historicidade como verossimilhança, do ponto de vista do espectador “médio" do século XVII (Barbier, 2007, p. 18), coloca a disputa num quadro de sociedade de corte, de disputa por uma dignidade áulica, com tudo que tal disputa comporta em competição por vantagens - como quer Elias - "imateriais". Como escreve o autor alemão, a sociedade burguesa pode até certo ponto desdenhar das demonstrações de status como "imateriais" às relações econômicas reais; para um aristocrata do Absolutismo, tais demonstrações imateriais de prestígio (as préseances) são o "capital" sobre o qual se fundam as posições materiais de subsistência mesmo (Elias, 1985:83-84)- o poder social e político efetivo, material. Como também lembra Elias, na sociedade aristocrática europeia do século XVII a posição social é até certo ponto juridicamente determinada, mas o título em si mesmo não tem efetividade senão na medida em que se traduz em uma demonstração de prestígio público (ELIAS, 1985, p. 79): o nobre de província, por mais antiga que seja a sua linhagem, não "vale" o que "vale" o membro da Corte, por recente que seja sua nobreza.

Como escrevia um moralista como La Bruyére, um cortesão, por mais que não trabalhe, nunca está desocupado: “a vida da Corte é um jogo sério, melancólico e aplicado. É preciso arranjar peças e baterias [de artilharia], ter um objetivo, segui-lo, interferir no do adversário, arriscar ocasionalmente [...]” (In: ELIAS, 1985, p. 97).

"Arriscar ocasionalmente": esbofetear um velho frágil para dar conta publicamente da sua fraqueza é algo moralmente reprovável, mas ainda assim, efetivo do ponto de vista da acumulação de demonstrações de força.

É certo que D. Rodrigo tem muito mais razões para atender seu pai e dispor-se a matar seu sogro presuntivo do que Romeu tinha para matar Teobaldo e vingar a morte de Mercúcio. Pois como diz o próprio D. Gomes a Rodrigo, ao aceitar o desafio ao duelo fatal, um filho tem o dever de vingar a honra paterna, ou perder o direito à própria vida:

Viens, tu fais ton devoir, et Le fils degénère

Qui survit un moment à l'honneur de son père.

[Vem, fazes teu dever. Degenera o rebento Que à honra de seu pai, sobrevive um momento.]

(II, ii, 441-442) 
Ainda assim, a vingança de D. Rodrigo é excessiva naquilo que tem de friamente premeditada: Romeu mata Teobaldo imediatamente após a morte de Mercúcio (que ele, Romeu, possibilitou inadvertidamente); Rodrigo mata o futuro sogro depois de uma longa meditação, em que ele se resolve ao duelo após expor um dilema pascaliano: vingar-se é por em movimento a roda da rixa de sangue; mas não fazê-lo é converterse em objeto de desprezo, mesmo o da própria amante:

Je dois à ma mâitresse aussi bien qu'à mon père:

$J$ ' attire en me vengeant sa haine et sa colère ;

$J$ ' attire ses mépris en ne me vengeant pas.

[Devo-me à minha amada assim como a meu pai ; Minha vigança o ódio e a cólera Ihes atrai;

Atraio o seu desdém, se não vingar-me o aço]

(I, vi, 322-324)

Justificada que seja, a vingança é excessiva: uma humilhação não mortal respondida com força letal. Para o espectador (burguês) moderno, pareceria mais justificável um assassinato cometido sob violenta emoção para vingar outra morte, do que uma vingança homicida fria cometida para expiar um mero ataque ao pundonor familiar. Mas para os contemporâneos de Corneille, o problema não se punha desta forma: Scudéry, o grande crítico de Corneille, escandalizado com o sucesso geral (tanto na "Corte" quanto na "Cidade") do Cid, expunha este sucesso da seguinte forma: "que um vapor de grosseria formado na plateia [reservada ao público burguês] tenha podido elevarse até às galerias [reservadas ao público nobre], que um fantasma tenha abusado da sabedoria em favor da ignorância, e da Corte assim como do Burguês, confesso que é um prodígio que me espanta" (In: BARBIER, 2007, p. 17). Ou seja: o público burguês da época reagiu, em princípio, mais favoravelmente às escolhas dramáticas - para nós, aparentemente bizarras - de Corneille do que o público propriamente aristocrático. Corneille parecia haver violado os preceitos do bom gosto aristocrático comumente aceito, muito cioso do decoro e da justa medida, e seria interessante perceber o que o fez cair no gosto do Terceiro Estado.

Ora, o Terceiro estado francês do século XVII era profundamente monarquista: as Guerras de Religião e as crises dinásticas concomitantes haviam criado um interesse difuso por uma única fonte de autoridade política que garantisse a paz civil. Formulações teóricas como as de Bodin respondiam a esta demanda social: não se tratava de sustentar uma monarquia "burguesa", mas de, preservando os privilégios feudais e corporativos, torná-los dependentes de um centro único de autoridade (WOOD, 2012, p. 164). Corneille introduz aqui uma cena (que não existia no texto espanhol de Guillen de Castro) em que D. Gomes, ao saber que o Rei lhe ordena desculpar-se a D. Diego, recusa-se e diz arrogantemente ao enviado do rei que a sua utilidade ao Estado o dispensa de tal necessidade:

Um jour seul ne perd pas um homme tel que moi. Que toute sa grandeur s'arme pour mon supplice Tout l'État périra, s'il faut que je périsse. 
[A um homem como eu, um só dia não perde.

Seja o seu poder todo ao meu suplício armado,

Tendo eu que perecer, perece todo o Estado.]

(II, i, 376-377)

Cena esta que parece estar posta aí para jogar com o monarquismo popular e induzir na plateia o ódio à arrogância de certa nobreza.

Contrariamente a Shakespeare, que joga em Romeu e Julieta com uma situação com uma situação passavelmente quotidiana - a da mésaillance como oposição involuntária entre os afetos do individuo e a norma do grupo a que pertence, e das condições a partir da qual a norma pode sofrer uma transformação que dê conta dos direitos do indivíduo - Corneille faz algo bem diverso. Ele utiliza a situação excepcional do Cid para fazer um hapax - o caso limite, único, irreprodutível, que, no entanto, coloca a questão dos limites últimos da lei moral e da sua validade geral a partir deste limite. Vingar uma ofensa pública feita ao próprio pai é algo perfeitamente admissível a partir do ethos aristocrático: la lessive de l'honneur ne se coule qu'avec du sang, a honra suja só é limpa com sangue. O que torna a conduta de D. Rodrigo inumana - do mesmo modo que a do herói legendário romano (e da peça seguinte de Corneille) Horácio, que decide da vitória romana contra os Curiácios de Alba Longa num combate singular - está em que este, para poder matar, tenha que pisar ao chão as suas afeições particulares, quando o mesmo Horácio mata a irmã que lamenta a morte do seu noivo, um dos Curiácios. Como escreve Maquiavel, falando do caso de Horácio nos Discursos, jogar a sorte do Estado num duelo singular (como teria feito o rei Túlio) é reprovável, por implicar em confiança cega na Fortuna (BARBIER, 2007, p. 44). Corneille, no entanto, ao falar de dois casos altamente improváveis em duas peças, utiliza estes dois eventos fortuitos e únicos apenas para afirmar uma regra geral: é a lei régia que deve prevalecer em última instância.

Este programa político é uma espécie de desenvolvimento desigual e combinado: se Shakespeare fala da gênese do Estado moderno como garantia das liberdades de um indivíduo "protoburguês", genérico e indiferenciado, em Corneille o poder do Estado é o de um árbitro dos privilégios hierárquicos, racionalizados e organizados, mas jamais abolidos. Como resume Perry Anderson, o caráter "barroco" do Absolutismo dos reis Bourbons - "onde várias composições fundem-se e opõem-se umas as outras até serem absorvidas numa composição magnífica" - encontra-se no fato de que nesta variedade específica de Absolutismo, a "lenta mas inexorável unificação da classe nobre" combina-se com "a integração da Burguesia nascente dentro dos circuitos do estado feudal" (ANDERSON, 1980, p. 96-97), i.e. numa hierarquia unificada de privilégios, exceções e casos especiais.

Bem entendido, pode-se até dizer que Corneille, diante dos seus contemporâneos, estava fazendo teatro mais do que meramente "engajado", no sentido de estar propondo uma agenda política polêmica: o programa político do Absolutismo sans phrase, com a sua hipertrofia semidivina da figura régia, o "absolutismo providencialista" (XAVIER; HESPANHA, s.d., p. 135), que era não só uma especialidade francesa, uma inovação com circulação restrita nas demais monarquias europeias, como algo sujeito à críticas 
e contestações mesmo na França - especialmente por reduzir o peso político do privilégio aristocrático. O que talvez explique exatamente porque Corneille dilua o peso polêmico de sua agenda política apelando precisamente para o desenvolvimento do que seria, de partida, uma tragédia, na direção de um desenvolvimento "cômico", quase paródico mesmo....

\section{A Questão do Indivíduo e sua inserção}

Le Cid toca em cheio num problema que Romeu e Julieta apenas tangencia: o de que o amor romântico, no seu limite, não dissolve apenas a identidade social, mas a individual (BENZAQUEN DE ARAUJO; VIVEIROS DE CASTRO, 1977, p. 154): deixados a si mesmos, Romeu e Julieta só podem aspirar à morte, à sua comum dissolução numa descarga pulsional. Como escreve Freud, o amor é a fonte mais imediata da felicidade humana - e, precisamente por isso é que nunca somos mais frágeis do que quando amamos. Ximena, antes do duelo fatal, descreve a situação do seu amante vis-à-vis dela mesma: ela não pode admitir o assassinato do pai, mas ao mesmo tempo o reconhece como justificável, para sua própria vergonha e constrangimento:

S'il ne m'obéit point, quel comble à mon ennui !
Et s'il peut m'obéir, que dira-t-on de lui ?
Étant né ce qu'il est, souffrir un tel outrage!

Mon esprit ne peut qu'être ou honteux ou confus

De son trop de respect ou d'un juste refus

[Se não me obedecer, ah, que auge de aflição!

E se me obedecer, dele o que não dirão!

Minha alma há de se ver na vergonha ou confusa,

Com o excesso de respeito, ou a lídima recusa.]

(II, iv, 487-492)

Nos termos da honra aristocrática, o casamento de Ximena e Rodrigo é desde já impossível, na medida em que a honra exige a vingança familiar à afronta recebida; se Rodrigo sacrificasse esta noção de honra em favor do seu desejo individual, ele despiria de si aquilo que o faz ser ele mesmo, desonrar-se-ia,e sua aliança tornar-seia indesejável. Romeu e Julieta, unidos na morte, não tem de dar conta de uma vida comum; Rodrigo e Ximena terão de fazê-lo, se desejarem unir-se em vida.

Quando o duelo entre Rodrigo e D. Gomes já começou, o Rei D. Fernando, em conversa com o nobre D. Sancho, informa que já decidiu punir D. Gomes seriamente por sua insolência, e quando D. Sancho lembra ao rei a folha de serviços de seu vassalo, D. Fernando responde que

... quoi qu'on veuille dire, et quoi qu'il ose croire

Le Comte à m'obéir ne peut perdre sa gloire.

[E por mais que se diga, e por mais que ele o creia, Obedecer, do conde a glória não alheia.]

(II, vi, 601-602) 
Obedecer à Lei do Estado - ao Monarca como sujeito putativo do Imperativo Ético - é não apenas útil e necessário como principalmente desejável, pois apenas no Monarca que reside o reconhecimento do indivíduo singular. A obediência, mais do que uma maneira de honrar, é uma maneira de garantir-se o ser honrado. No Horácio, é o lendário rei de Roma Túlio [Hostílio] que reconhece, en passant, o mérito de Horácio e o "anistia” do assassinato de sua irmã: Ta vertu met ta gloire au-dessus de ton crime. - expressando a noção hobbesiana de que é o Estado que, mais do que reconhecer, institui o justo e o injusto. Mas, precisamente por isso, Corneille hesitará bastante entre apresentar o "excesso de zelo" de um súdito agindo por conta própria como algo louvável, e no verso seguinte - Sa chaleur généreuse a produit ton forfait ("o ardor da tua virtude generosa produziu teu crime") - esta "virtude" (no sentido maquiavélico da palavra) é qualificada pelo poeta, dependendo das variantes do texto impresso, ora como "generosa", ora como perigosa.... (BARBIER, 2007, p. 45). É mais conveniente uma solução mais regular: é virtuoso aquilo que o Estado - no caso, o Monarca - não apenas reconheceu ex post, mas instituiu ex ante. Em outra tragédia de Corneille, Cinna ou a Clemência de Augusto, de 1640 - que era a peça favorita de Napoleão Bonaparte - o personagem título só será correspondido no seu amor por sua amada Emília se matar o imperador romano Augusto, assassino do pai de Emília. Depois de uma série de quiproquós trágicos, Augusto toma conhecimento da conspiração quando esta é ainda mera inconfidência e reage - promovendo Cina ao consulado, casando-o com Emília e tomando-o, por iniciativa própria, como amigo pessoal : Soyons amis, Cinna, c'est moi qui t'en convie - assim exercendo a capacidade de iniciativa que Maquiavel considerava ser a grande virtude do Príncipe. Napoleão, que gostava desta cena a contragosto, uma vez disse que a atitude de Augusto lhe repugnava como sentimento, mas que ele a admirava enquanto cálculo (ENGLUND, 2005, p. 261-262) - como forma de um ditador bonapartista, em lugar de ceder a uma demanda, conceder soberanamente aquilo que talvez tivesse de fazer de qualquer maneira.

O Cid, Horácio, Cina: todos figuras do grande aristocrata cujos afetos precisam ser domesticados e postos a serviço do Estado. Em Shakespeare, uma vez a lógica do sangue subsumida na "sombria paz", restou ao Estado administrar a paz civil, a contradições entre as paixões e os interesses: instituir aquilo que, na linguagem comum do século o XVIII chamar-se-ia uma sociedade "policiada". Em Corneille, tal paz nunca está garantida: os afetos individuais necessitam ser vigiados de perto para que não retomem seu curso destrutivo. Emília atrai Cina a uma conspiração potencialmente suicida porque esta é a única maneira de corresponder ao seu amor sem renunciar à sua vingança e ao seu dever: Je lui prescris la loi que mon devoir m'impose. E Cina aceita esta proposta suicida tanto por amor quanto por estar dominado pela mesma lógica da vingança. Como confessará Emília a Augusto: Une haine plus forte à tous deux fit la loi.

Não que estes personagens sejam são meros representantes, tokens de uma posição hierárquica ${ }^{2}$; o que os caracteriza é exatamente o fato de se encontrarem torcidos entre as exigências da sua posição social e seus desejos particulares: sem essa contradição, Le Cid teria que ser uma tragédia sobre o dever filial e a realização 
concreta de uma vingança - ao estilo dos 47 ronins da lenda japonesa; a paralisia de Rodrigo e Ximena, divididos entre o amor e a honra, seria inconcebível. Mas é precisamente essa tensão - e ao mesmo tempo sinergia - entre o desejo individual e a posição hierárquica, um e outro se opondo e sustentando-se mutuamente, que cria a tensão dramática da peça - mesmo na ausência de um desenvolvimento dramático e da repetição estática do mesmo dilema básico: o fato de que os protagonistas, divididos entre o desejo e o dever, estão condenados a permanecerem o tempo todo no mesmo lugar. É o que diz a Emília de Cinna no início da peça, quando pede (literalmente) aos seus desejos de vindita, os Impatients désirs d'une illustre vengeance, que a deixem respirar: Vous prenez sur mon âme un trop puissant empire;/ Durant quelques moments souffrez que je respire.

Aquilo que o lluminismo de Diderot considerava ser o principal defeito do Classicismo - o seu caráter estático, o seu artificialismo e ausência de verdadeira ação dramática (MILLER, 1971, p. 192) - é na verdade a expressão das condições sociais e políticas reais sobre as quais o Classicismo se apoia: o sujeito aristocrático da tragédia clássica, mais do que uma individualidade empírica, é uma abstração (REX, 1987, p. 173), uma posição institucional. Só que esta posição institucional jamais anula completamente o indivíduo empírico. No Japão do Shogunato Tokugawa, contemporâneo de Corneille, o enredo de Le Cid seria plenamente compreensível, mas não o seu desenvolvimento: um japonês do século XVII poderia admitir indiferentemente que Ximena matasse o Cid ou que o Cid matasse o pai de Ximena - desde que, em qualquer dos casos, ao satisfazerem o seu dever filial, cada um dos dois pagasse pelo seu crime de insubordinação cometendo voluntariamente - e com todo o aparato - haraquiri (seppuku) diante do Rei. Qualquer outra conclusão, do ponto de vista da ética samurai do dever - bushido - pareceria aberrante. Numa sociedade ainda aristocrática e feudal sans phrase, o conflito trágico entre indivíduo e sociedade só pode ainda resolver-se da mesma maneira que na tragédia grega: através da morte e na morte. Só que é este elemento aberrante da contradição entre papel social e individualidade empírica - e da resolução aparentemente paródica, até mesmo farsesca, desta contradição - que constitui o ethos da peça francesa.

\section{Sobre soluções e conclusões}

A ausência de ação nestas peças corresponde a esta situação típica: um dilema é um dilema na medida em que, por si só, não leva a nada que seja diferente dele mesmo; é a reprodução de uma situação desconfortável, de uma impossibilidade. Esta situação necessita ser resolvida por um Deus ex machina, e nas três peças de que falamos aqui, é sempre a figura do monarca que cumpre tal papel.

Pela regra aristotélica das três unidades (tempo, lugar, ação) - mais exatamente, pela interpretação radical que o Classicismo francês dava a esta regra - uma tragédia deve mostrar apenas uma ação, que se desenrola num único lugar e no espaço de 24 horas. Le Cid não é a história das desventuras amorosas de D. Rodrigo e Ximena: mal os amantes infelizes tem o tempo de constatar a sua infelicidade, surge a solução dramática - Sevilha é invadida por uma frota moura que sobe o rio Guadalquivir . Trata- 
se de uma licença poética (a capital de Castela no século XI era Burgos, e Sevilha encontrava-se sob controle árabe) que permite reter as unidades de tempo e de lugar; os mouros têm de materializar-se instantaneamente para que a ação dramática desenrole-se no tempo exigido. É também uma maneira de subordinar o elemento da paixão amorosa à conclusão basicamente política da peça.

Os mouros não cumprem outra função que não seja a de permitir ao herói realizar um feito de armas que o torne indispensável a seu príncipe. Estamos na França de Luis XIII, com o Edito de Nantes em pleno vigor - e com ele a liberdade de consciência passiva, a aceitação do Protestantismo enquanto leal ao Trono. O elemento do conflito religioso, na peça de Corneille, não existe, e o enredo encontra-se rigorosamente "secularizado"; os mouros apenas surgem e são devidamente derrotados, sem aparecerem em cena; as façanhas de D. Rodrigo são apenas narradas. Justifica-se que a confidente de Ximena, Elvira, descreva a situação ironicamente dizendo que os mouros chegaram apenas para fugirem:

Les Maures devant lui n'ont paru qu'à leur honte;

Leur abord fut bien prompt, leur fuite encore plus prompte;

[Dos Mouros foi, ante ele, a derrota de monta;

Rápido o desembarque, e a fuga ainda mais pronta; ]

(IV, i, 1.105-1.106)

Compare-se com a peça de Guillen de Castro, na qual D. Rodrigo torna-se o Cid num longo processo que inclui a formação de um exército e um principado privados, assim como um duelo judiciário singular com o campeão do Rei de Aragão Martin González, em que estão em jogo a posse da fortaleza de Calahorra ... e a mão de Ximena, que havia prometido casar-se com quem lhe trouxesse a cabeça do Cid... $\mathrm{E}$ Guillen de Castro conclui a peça com D. Rodrigo apresentando-se diante de Ximena e da família real de Castela:
pues yo vengo de Aragón,
y no vengo sin cabeza,
y la de Martín González
está en mi lanza allí fuera;
y ésta le presento agora
en sus manos a Jimena.
$Y$ pues ella en sus pregones
no dijo viva ni muerta,
ni cortada, pues le doy
de Rodrigo la cabeza,
ya me debe el ser mi esposa

A ferocidade dos versos acima tem bem mais historicidade que os alexandrinos do poeta francês: Rodrigo é o senhor feudal que conseguiu, com a sua milícia privada (mesnada) e a sua habilidade individual, abrir caminho a fogo e ferro para impor-se como vassalo de primeira linha do seu rei (ELIAS, 1993, p. 120, II) e qualificar-se a uma aliança por matrimônio - praticamente um estupro legal - que o encaixará duradouramente 
no primeiro círculo do poder. Para uma sensibilidade política da Idade Moderna, no entanto, tal espécie de herói seria dificilmente aceitável. Impor-se a um rei e obter uma aliança matrimonial com um bando de homens armados e uma cabeça na ponta de uma lança não são coisas compatíveis com o programa político do Absolutismo antes são seu contrário. Sob a pluma de Corneille, o Cid irá converter-se, de cavaleiro medieval truculento e turbulento, em cortesão absolutista respeitoso.

Na conclusão de Le Cid, o rei D. Fernando, querendo recompensar o herói, arranja para que ele trave um duelo mais ou menos fictício com o campeão de Ximena D. Sancho, duelo este que o Cid vence, poupando seu adversário e fazendo com que ele o preceda para anunciar uma vitória mentirosa diante de Ximena, que rejeita a sua aliança:

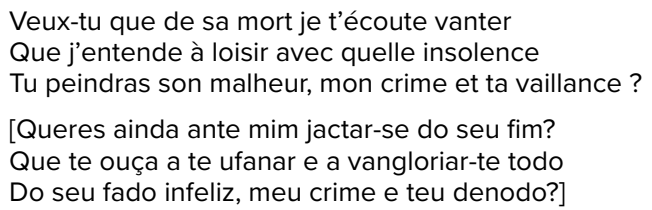

$(\mathrm{V}, \mathrm{v}, 1.720-1.722)$

Diante da confissão de amor (histérica) de Ximena, o rei D. Fernando autoriza o seu casamento com o Cid, sob a condição de que este se encarregue de combater os mouros por um ano, antes da realização do enlace. Solução que escandaliza Ximena, que confessa o seu desejo por meio de uma litotes (Rodrigo tem qualidades que "ela não pode desprezar") e levanta uma objeção pertinente: se meu casamento é necessário ao Estado, como evitar, neste caso, o escândalo?

Rodrigue a des vertus que je ne puis haïr :

Et quand un roi commande, on lui doit obéir.

Mais, à quoi que déjà vous m'ayez condamnée?

Pourrez-vous à vos yeux souffrir cet hyménée?

Et quand de mon devoir vous voulez cet effort,

Toute votre justice en est-elle d'accord?

Si Rodrigue à l'État devient si nécessaire,

De ce qu'il fait pour vous dois-je être le salaire,

Et me livrer moi-même au reproche éternel

D'avoir trempé mes mains dans le sang paternel ?

[Rodrigo prendas tem a que ódio não sei ter;

E quando manda um rei, temos de obedecer.

Mas, ainda que tenhais julgado já meu pleito,

Há de ser por vós mesmo este himeneu aceito?

E impondo a meu dever que tal esforço aborde,

Vossa justiça toda a em tal de estar conforme?

Se Rodrigo ao Estado é assim tão necessário,

Do que ele fez por vós, devo eu ser o salário

E me entregar eu mesma à censura eternal

De ter banhado as mãos no sangue paternal?]

(V, vii, 1.803-1.812) 
Rodrigo encontra-se perdoado por ter-se provado necessário ao Estado- e Ximena, consequentemente, obrigada a renunciar à lealdade privada em favor do interesse público (GREENBERG, 1986, p. 53). É o argumento de Hobbes no Leviatã quanto à natureza do pacto que constitui o Estado como uma autorização condicionada: o Soberano pode fazer o que quiser - exceto falhar na sua tarefa de preservar a vida e a segurança (WOOD, 1997, p. 108-109). É o mesmo argumento que, no Cinna, a imperatriz Lívia usa para justificar a política de Augusto e as violências que o levaram ao poder, aformando que entre as prerrogativas do poder está precisamente a de, senão reescrever o passado, a de legitimá-lo retrospectivamente, converter ex post em ação virtuosa e necessária - e virtuosa porque necessária - aquilo que foi caracterizado ex ante como crime :

Tous ces crimes d'État qu'on fait pour la couronne, Le ciel nous en absout alors qu'il nous la donne,

Et dans le sacré rang où sa faveur l'a mis, Le passé devient juste et l'avenir permis. Qui peut y parvenir ne peut être coupable ; Quoi qu'il ait fait ou fasse, il est inviolable:

Nous lui devons nos biens, nos jours sont en sa main, Et jamais on n'a droit sur ceux du souverain.

[Aos crimes de Estado, o Céu dá absolvição quando dá a coroa; e quando seu favor nos colocou numa posição sagrada, o passado torna-se justo e o futuro lícito. Quem chega a tal posição não pode ser culpado: tenha feito ou faça o que quiser, é inviolável; devemos-lhes nossos bens, nossos dias estão na sua mão, e não há direitos que se coloquem sobre os do soberano.]

O Soberano sendo o fundamento não só da moralidade, mas também o fundamento das hierarquias sociais- e, com elas, da propriedade e das relações de produção. No final do Le Cid, se D. Fernando justifica a autorização de casamento a Ximena alegando o simples costume e sua consagração pelo tempo, que assez souvent $a$ rendu legitime/ Ce qui semblait d'abord ne se pouvoir sans crime - para Rodrigo ele é mais explícito:

Pour vaincre un point d'honneur qui combat contre toi, Laisse faire le temps, ta vaillance et ton roi.

[Se ainda a ti se opõe de um ponto de honra a lei, Deixa que o vença o tempo, o teu braço e o teu rei.]

( $V$, vii, 1.839-1.840)

Note-se aqui o papel da cesura - e da antítese que ela produz - no meio do alexandrino: o primeiro hemistíquio proclama a liberdade individual garantida pelo Estado (Iaisse faire... que o Liberalismo econômico do século XVIII, num outro contexto, transformará em divisa); o segundo hemistíquio, estabelece que esta liberdade individual é um privilégio, uma prerrogativa concedida pelo governante: a cortina fecha-se e a última palavra que se ouve é roi - enfatizada pela acentuação tônica na última sílaba. 


\title{
Contestações
}

Uma geração depois de Corneille, Racine, na sua peça Britannicus, terá outras ideias sobre as relações entre o Estado e a Sociedade. Nesta peça situada na Antiguidade Imperial Romana, é quando Nero resolve-se a matar o personagem principal, seu irmão adotivo, para apoderar-se do poder - e da amada de ambos, Júnia - que ele começa a soçobrar no exercício da autocracia que o levará ao matricídio e à sua própria perda, como antecipa, aliás, a sua mãe Agripina, ao prever a seu filho seu futuro matricídio:

\author{
Poursuis. Tu n'as pas fait ce pas pour reculer. \\ Ta main a commencé par le sang de ton frère ; \\ Je prévois que tes coups viendront jusqu'à ta mère [...] \\ Mais je veux que ma mort te soit même inutile ; \\ $\mathrm{Ne}$ crois pas qu'en mourant je te laisse tranquille. \\ [Prossegue: passo tal não deste p'ra recuar. \\ Tua mão começou pelo sangue fraterno; \\ Prevejo que virá até o seio materno [...]. \\ Mas saibas que o meu fim não aproveitarás; \\ Não penses que ao morrer hei de deixar-te em paz.]
}

Entre Corneille e Racine existia o intervalo de uma geração apenas - o que foi suficiente para que a agenda política tivesse se transformado completamente. Racine, escrevendo durante o auge do reinado pessoal de Luís XIV, defrontou-se com um momento histórico em que o Absolutismo francês, ao subordinar tudo e todos à Razão de Estado, ainda assim fracassou na sua ambição hegemônica diante da emergência do Capitalismo, do poder combinado das Burguesias britânica e holandesa: pois "a hora da supremacia de Versalhes, que parecia tão próxima [...] nunca chegou"(ANDERSON, 1980, p. 106). Apesar de todo o esforço dos Bourbons em intensificarem ${ }^{3}$ a mobilização da França aristocrática, o projeto absolutista de subordinar o Interesse ao Privilégio, a Concorrência à Hierarquia falhou, e a rejeição raciniana do Absolutismo em favor do quietismo político e do ascetismo extramundano do jansenismo (GOLDMANN, 1959) ${ }^{4}$ antecipava rejeições mais radicais, três quartos de século no futuro. $O$ foro interior do cidadão burguês contesta a hegemonia da Razão de Estado (KOSELLECK, 1999, p. 38).

Para Corneille, contemporâneo de Luís XIII e do jovem Luis XIV, do cerco de La Rochelle e da Fronda, a ideia de que uma proto-"Sociedade Civil" pudesse contestar o poder do Estado, que a "Cidade" pudesse criticar a "Corte", pareceria absurda, especialmente pelo fato de que tal Sociedade Civil precisaria passar por um processo prévio de "domesticação" hobbesiana.

\section{Conclusão}

Desde pelo menos Stendhal (1927, p. 26) Shakespeare, ao colocar as pulsões do indivíduo a frente das exigências do Sangue, nos parece mais próximo de Racine do que Corneille, contemporâneo mais velho do dramaturgo jansenista. Mas quem é o "indivíduo" de Shakespeare? Nele não começa tão alto como em Corneille; mas certamente não inclui o camponês ou o artesão. Na abertura de Júlio César, o "vulgo 
vil sem nome" deseja aclamar César, e os tribunos Flávio e Marulo ordenem-Ihe que volte para casa em penitência (See whether their basest metal be not moved - "vede se não derreteu o baixo metal de que são feitos") ${ }^{5}$. 0 indivíduo shakespeariano não é sans phrase; é o indivíduo sujeito a um processo prévio de "domesticação" e policiamento iniciado sob o Absolutismo da era Tudor, e continuado sob outras formas e com outros objetivos pelo Estado Burguês emergente.

Com toda a sua panóplia de liberdades individuais burguesas, a Inglaterra puritana do século XVII e a Holanda contemporânea não foram sociedades menos "policiadas" e repressivas que as monarquias absolutistas suas coetâneas. Se Shakespeare nos parece mais "democrático" que Corneille, é apenas porque a Inglaterra se encontrava então mais adiantada que a França no que diz respeito à construção de uma "sociedade civil" policiada: como nota Anderson, a pequena-nobreza e os interesses mercantis ingleses, motor da Revolução de 1640, se opunham-se à hierarquia áulica de Carlos I, ao mesmo tempo eram eles mesmos parte de uma hierarquia alternativa centralizada no Parlamento (ANDERSON, 1980, p. 140), e cuja legitimidade política estava expressa no apagamento da pessoa do Rei diante da noção da Coroa como ente de caráter puramente jurídico e abstrato - "um corpo compósito, um agregado do Rei e de todos os responsáveis pelos direitos inalienáveis da Coroa e do Reino" (KANTOROWICZ, 1981, p. 381). O individualismo político e social do que seria a sociedade burguesa moderna formou-se a partir das bases lançadas pelas hierarquias absolutistas. $O$ que houve foi a passagem de uma hierarquia fundada no acaso nobiliárquico \& no arbítrio real para uma hierarquia fundada em atributos gerais e impessoais - como na tipologia de Spinoza, que considerava democráticos todo Estado em que a condição de sujeito político estivesse estabelecida em lei, por critério impessoal, mesmo se o número dos que alcançassem tal condição fosse menor do que numa aristocracia fundada na simples cooptação (ESPINOSA, 2009, p. 137-138).

Escrever sobre textos que há séculos fazem parte do Canon literário implica certamente em remover grande parte das camadas de sentido que lhe foram adicionadas, tentar chegar ao núcleo original na sua raridade e unicidade; mas significa também perceber a persistência de uma problemática. Que Napoleão I talvez o arquétipo do governante moderno como líder plebiscitário - ainda encontrasse utilidade em refletir sobre Corneille e as virtudes do cálculo político como instrumento legitimador diz muito sobre a natureza elusiva do interesse universal e sua relação com os particulares. O Estado moderno nascente, ao opor à lógica da vendetta privada a preeminência da Lei, da esfera pública, suas prioridades e valores, tornou possível o surgimento dos indivíduos modernos, suas paixões e interesses. Mas para que tal gênese do indivíduo fosse possível, o Estado moderno hierarquizou a Sociedade, de acordo com uma agenda, claramente, de classe. Não é indivíduo quem o quer - mas quem está autorizado a sê-lo. E, neste sentido, Romeu e Julieta desenrola-se sobre o pano de fundo de Le Cid, das origens absolutistas e heteronômicas do Estado burguês moderno. Que as hierarquias tornaram-se ser mais objetivas e impessoais, e mais flexíveis é certo. Mas o fato é que ainda estamos bem longe do "Indivíduo" como sujeito universal. Talvez venha daí o encanto mais perene de Romeu e Julieta - daquilo que, no texto, ainda é promessa emancipatória. 


\section{Referências}

ANDERSON, Perry. Lineages of the Absolutist State. Londres: Verso, 1980.

AUERBACH, Erich. Mimesis. São Paulo: Perspectiva, 1987.

BARBIER, Diane (ed.) Penser l'Histoire. Rosny-sous-bois: Bréal, 2007.

BENZAQUEN DE ARAUJO, Ricardo; VIVEIROS DE CASTRO, Eduardo. "Romeu e Julieta e a origem do Estado". In: VELHO, Gilberto. Arte e Sociedade: ensaios de sociologia da arte. Rio de Janeiro: Zahar Editores, 1977, p. 130-169.

CASTRO, Guillén de. Las Mocedades del Cid. Disponível em: http://biblioteca.org.ar/ libros/89209.pdf. Acessado em 5/04/2017.

CORNEILLE, Pierre. Le Cid. Paris: Hachette, 1959.

CORNEILLE, Pierre. Le Cid. Trad. Portuguesa de Jenny Klabin Segall. O Cid e Horácio. Rio de Janeiro: Ediouro, s.d.

CORNEILLE, Pierre. Cinna. Disponível em https://www.atramenta.net/lire/cinna/3444 Acessado em 5/04/2017.

ELIAS, Norbert. La Société de Cour. Paris: Flammarion, 1985.

ELIAS, Norbert. O Processo Civilizador. Rio de Janeiro: Jorge Zahar, 1993.

ENGLUND, Steven. Napoleão - uma biografia política. Rio de Janeiro: Zahar, 2005.

ESPINOSA, Baruch de. Tratado Político, São Paulo: Martins Fontes, 2009.

XAVIER, Ángela Barreto; HESPANHA, António Manuel. "A representação da Sociedade e do Poder". In: HESPANHA, António Manuel (coord.); MATTOSO, José (dir.) História de Portugal. IV - O Antigo Regime (1620-1807). Lisboa: Ed. Estampa, s.d.

GOLDMANN, Lucien. Le Dieu Caché. Paris: Gallimard, 1959

GREENBERG, Mitchell. Corneille, Classicism and the Ruses of Symmetry. Cambridge U. Press, 1986.

KANTOROWICZ, Ernst. The King's Two Bodies. Princeton U. Press, 1981.

KELLER, Marcus. Figurations of France: Literary Nation-Building in Times of Crisis (1550-1650). Lanham (US): University of Delaware Press, 2011.

KOSELLECK, Reinhart. Crítica e Crise. Rio de Janeiro: UERJ/Contraponto, 1999.

MILER, Arnold. "The Annexation of a Philosophe: Diderot in Soviet Criticism 1917-1960". In: FELLOWS, Otis; GUIRAGOSSIAN, Diana (eds.). Diderot Studies XV. Genebra: Droz, 1971.

RACINE, Jean. Britannicus. Disponível em https://www.atramenta.net/lire/

britannicus/394. Acessado em 5/04/2017. 
RACINE, Jean. Britannicus. Trad. portuguesa de Jenny Klabin Segall. AndrômacaBritânico. São Paulo: Martins, 1963.

REX, Walter E. The Attraction of the Contrary: Essays on the Literature of the French Enlightenment. Cambridge U. Press, 1987.

STENDHAL. Racine et Shakespeare. Paris: Hatier, 1927.

WOOD, Ellen Meikisins. A Trumpet of Sedition: political Theory and the Rise of Capitalism. New York: New York University Press, 1997.

WOOD, Ellen Meikisins. From Citizens to Lords. Londres: Verso, 2008

WOOD, Ellen Meikisins. Liberty and Property. Londres: Verso, 2012.

VEYNE, Paul. L"Empire Gréco-Romain. Paris: Seuil, 2005.

\section{Notas}

1 Fora para o texto do Cinna e um texto em prosa do mesmo Corneille, utilizei as traduções Corneille e Racine feitas por Jenny Klabin Segall na década de 1960, que são excelentes e metrificadas, mas conservei os originais, tive em vista que o encanto dos textos reside, em grande parte, na musicalidade própria da língua francesa do Grand Siècle.

2 O que Francis Hu chama de "centrado na situação" em oposição a "centrado no indivíduo". (apud BENZAQUEN DE ARAUJO; VIVEIROS DE CASTRO, 1977, p. 144).

3 Intensificação esta que, segundo Serge Doubrovsky, regeria o desenvolvimento da noção corneilliana do Herói, do Cid a Horácio (apud KELLER, 2011, p. 187).

4 O desfecho de Britannicus, com Júnia refugiando-se entre as Virgens Vestais, numa mascarada pagã e romana da prática cristã de encerramento num convento, é uma licença poética que sublinha a rejeição do mundo (GOLDMANN, 1959, p. 368).

5 Contrastar com o elogio fúnebre de Bruto que fecha a peça: [....] and the elements/So mix'd in him that Nature might stand up/And say to all the world 'This was a man!'

Carlos Eduardo Rebello de MENDONÇA é Doutor em Sociologia pelo IUPERJ (1996) e Professor Titular da Universidade do Estado do Rio de Janeiro, onde é membro do Grupo de Pesquisa sobre Arte, Cultura e Poder. 